\title{
WPLYW TEMPERATURY NA WŁAŚCIWOŚCI DYNAMICZNE RAM Z LEPKOSPRĘŻYSTYMI TŁUMIKAMI DRGAŃ
}

\begin{abstract}
W pracy omawia się wpływ temperatury na charakterystyki dynamiczne konstrukcji z wbudowanymi lepkosprężystymi tłumikami drgań. Właściwości tłumików są opisywane uogólnionym modelem Maxwella, a parametry modelu są funkcjami temperatury panującej w tłumiku. Wykorzystuje się zasadę superpozycji czasowotemperaturowej. Charakterystyki dynamiczne konstrukcji z tłumikami drgań wyznacza się jako rozwiązanie problemu własnego. Podano i przedyskutowano wyniki przykładowych obliczeń.
\end{abstract}

Słowa kluczowe: drgania konstrukcji, tłumiki drgań, charakterystyki dynamiczne, wpływ temperatury

\section{Wstęp}

W wielu przypadkach amplitudy drgań wiotkich konstrukcji poddanych wymuszeniom dynamicznym są zbyt duże i należy je zmniejszyć. Jednym ze sposobów redukcji tego typu drgań jest wbudowanie w konstrukcję tłumików drgań. Przegląd możliwych do zastosowania tłumików jest podany w pracach [1, 2]. Do tego typu urządzeń charakteryzujących się wysoką skutecznością przy stosunkowo prostej budowie zalicza się tłumiki lepkosprężyste. Za pomocą tłumików tego rodzaju można efektywnie redukować drgania konstrukcji budowlanych. Wadą tłumików lepkosprężystych jest to, że ich właściwości zależą od częstości wymuszenia i temperatury materiału lepkosprężystego z którego zbudowany jest tłumik. Zmiana temperatury tłumika może być spowodowana zmianami temperatury jego otoczenia lub być efektem zjawiska tzw. samonagrzewania, czyli wzrostu temperatury wywołanego długotrwałą, nieprzerwaną pracą tłumika w trakcie działania np. huraganowego wiatru na konstrukcję.

\footnotetext{
${ }^{1}$ Autor do korespondencji/corresponding author: Maciej Przychodzki, Instytut Konstrukcji Budowlanych Politechniki Poznańskiej, ul. Piotrowo 5, 60-688 Poznań, tel. 616652697, email: maciej.przychodzki@put.poznan.pl

${ }^{2}$ Roman Lewandowski, Instytut Konstrukcji Budowlanych Politechniki Poznańskiej, ul. Piotrowo 5, 60-688 Poznań, tel. 616652472, email: roman.lewandowski@ put.poznan.pl
} 
Zależność właściwości tłumików lepkosprężystych od częstości wymuszenia jest uwzględniana w opisie matematycznym tłumików (porównaj [1]). Prace zmierzające do uwzględnienia wpływu temperatury są natomiast $\mathrm{w}$ początkowym stadium. Wpływ temperatury badano $w$ pracach [3-8]. W pracy [3] podano empiryczne zależności opisujące zmiany sztywności tłumika i jego współczynnika strat od częstości wymuszenia i temperatury, a w pracy [6] analizowano proces nagrzewania się tłumika wykonującego długotrwałe drgania okresowe.

W pracy analizuje się wpływ temperatury tłumików na charakterystyki dynamiczne konstrukcji z wbudowanymi lepkosprężystymi tłumikami drgań. Zachowanie tłumików jest opisywane za pomocą uogólnionego modelu Maxwella, a do opisu wpływu temperatury używa się zasadę proporcjonalności temperaturowo - częstotliwościowej omówioną m.in. w [6].

\section{Opis tłumików uwzględniający wpływ temperatury}

Zakłada się, że tłumiki lepkosprężyste są opisywane klasycznym, uogólnionym modelem Maxwella pokazanym na rys. 1 . Model ten otrzymuje się poprzez połączenie modeli prostszych, czyli tzw. prostego modelu Kelvina oraz szeregu połączonych z nim równolegle prostych modeli Maxwella. Elementami składowymi obu modeli prostych są element sprężysty i element lepki. W przypadku modelu Kelvina oba elementy są połączone równolegle, a w przypadku modelu Maxwella - szeregowo.

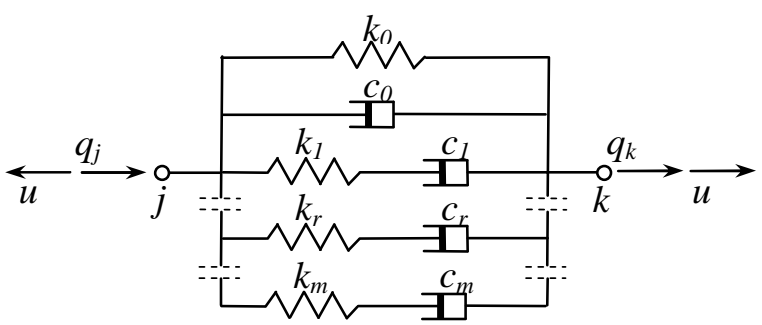

Rys. 1. Schemat uogólnionego modelu Maxwella

Fig. 1. A scheme of the genralized Maxwell model

Całkowita siła w tłumiku $u(t)$ jest sumą sił w poszczególnych elementach $u_{r}(t),(r=0,2, \ldots, m)$, tzn.

$u(t)=\sum_{r=0}^{m} u_{r}(t)$

Siła w elemencie Kelvina dana jest wzorem:

$u_{0}(t)=k_{0}\left(q_{k}(t)-q_{j}(t)\right)+c_{0}\left(\dot{q}_{k}(t)-\dot{q}_{j}(t)\right)$ 
a siła w r-tym elemencie Maxwella spełnia równanie:

$$
u_{r}(t)+\tau_{r} \dot{u}_{r}(t)=k_{r} \tau_{r}\left(\dot{q}_{k}(t)-\dot{q}_{j}(t)\right)
$$

gdzie symbolami $k_{r}, c_{r}$ i $\tau_{r}=c_{r} / k_{r}$ oznaczono odpowiednio: sztywność, współczynnik tłumienia i czas relaksacji elementu o numerze $r$ (patrz rys. 1), a $q_{k}(t)$ i $q_{j}(t)$ oznaczają przemieszczenia końców tłumika.

Jeżeli tłumik wykonuje ustalone drgania harmonicznie wymuszone to:

$$
\begin{aligned}
& u(t)=U e^{i \lambda t}, \quad u_{0}(t)=U_{0} e^{i \lambda t}, \quad u_{r}(t)=U_{r} e^{i \lambda t} \\
& q_{k}(t)-q_{j}(t)=x(t)=X e^{i \lambda t}
\end{aligned}
$$

gdzie $i=\sqrt{-1}$ jest jednostką urojoną, a $\lambda$ częstością wymuszenia.

Po podstawieniu (4) i (5) do równań (1) - (3) można, w sposób opisany w [2], otrzymać następujące wzory na moduł sztywności dynamicznej (moduł zachowawczy) $K^{\prime}(\lambda)$ i moduł tłumienia (moduł stratności) $K^{\prime \prime}(\lambda)$ :

$$
K^{\prime}(\lambda)=k_{0}+\sum_{r=1}^{m} k_{r} \frac{\tau_{r}^{2} \lambda^{2}}{1+\tau_{r}^{2} \lambda^{2}}, \quad K^{\prime \prime}(\lambda)=c_{0} \lambda+\sum_{r=1}^{m} k_{r} \frac{\tau_{r} \lambda}{1+\tau_{r}^{2} \lambda^{2}}
$$

Współczynnik stratności wyznacza się z zależności $\eta(\lambda)=K^{\prime \prime}(\lambda) / K^{\prime}(\lambda)$.

Moduły $K^{\prime}(\lambda)$ i $K^{\prime \prime}(\lambda)$ zależą od temperatury tłumika $T$, tzn. $K^{\prime}(\lambda, T)$, $K^{\prime \prime}(\lambda, T)$. Zależność obu modułów od temperatury uwzględnia się stosując zasadę proporcjonalności temperaturowo - częstotliwościowej, omówioną np. w [6,7]. Stwierdza ona, że moduły $K^{\prime}(\lambda, T)$ i $K^{\prime \prime}(\lambda, T)$ wyznaczone dla różnych temperatur mogą być powiązane ze sobą (przyrównane do siebie) przez przesunięcie (zmianę) aktualnej wartości częstości wymuszenia. Symbolicznie można tę zasadę zapisać w następujący sposób:

$$
K^{\prime}(\lambda, T)=K^{\prime}\left(\tilde{\lambda}=\alpha_{T} \lambda, T_{0}\right), \quad K^{\prime \prime}(\lambda, T)=K^{\prime \prime}\left(\tilde{\lambda}=\alpha_{T} \lambda, T_{0}\right)
$$

gdzie $T$ oznacza aktualną temperaturę, $T_{0}$ jest temperaturą odniesienia, $\tilde{\lambda}=\alpha_{T}(T) \lambda$ jest tzw. częstością zredukowaną, $\lambda$ jest aktualną częstością wymuszenia, a $\alpha_{T}(T)$ jest tzw. funkcją przesunięcia. Funkcje $K^{\prime}(\tilde{\lambda}), K^{\prime \prime}(\tilde{\lambda})$ i $\alpha_{T}(T)$ wyznacza się doświadczalnie [9].

Zastosowanie omawianej zasady w opisie uogólnionego modelu Maxwella pozwala na napisanie następujących zależności: 


$$
\begin{aligned}
& k_{0}+\sum_{r=1}^{m} k_{r} \frac{\tau_{r}^{2} \lambda^{2}}{1+\tau_{r}^{2} \lambda^{2}}=\tilde{k}_{0}+\sum_{r=1}^{m} \tilde{k}_{r} \frac{\tilde{\tau}_{r}^{2} \alpha_{T}^{2} \lambda^{2}}{1+\tilde{\tau}_{r}^{2} \alpha_{T}^{2} \lambda^{2}} \\
& c_{0} \lambda+\sum_{r=1}^{m} k_{r} \frac{\tau_{r} \lambda}{1+\tau_{r}^{2} \lambda^{2}}=\tilde{c}_{0} \alpha_{T} \lambda+\sum_{r=1}^{m} \tilde{k}_{r} \frac{\tilde{\tau}_{r} \alpha_{T} \lambda}{1+\tilde{\tau}_{r}^{2} \alpha_{T}^{2} \lambda^{2}}
\end{aligned}
$$

łączących stałe modelu $k_{0}, c_{0}, k_{r}, \tau_{r}$ wyznaczone w temperaturze $T$ ze stałymi $\tilde{k}_{0}, \tilde{c}_{0}, \tilde{k}_{r}, \tilde{\tau}_{r}$ wyznaczonymi w temperaturze odniesienia $T_{0}$. Zależności (8) i (9) będą spełnione jeżeli:

$$
k_{0}=\tilde{k}_{0}, \quad k_{r}=\tilde{k}_{r}, \quad c_{0}=\tilde{c}_{0} \alpha_{T}, \quad \tau_{r}=\tilde{\tau}_{r} \alpha_{T}
$$

W prosty sposób jest więc możliwe wyznaczenie stałych modelu dla różnych temperatur, o ile znamy stałe wyznaczone dla temperatury odniesienia i funkcję $\alpha_{T}(T)$. Funkcję przesunięcia $\alpha_{T}(T)$ zazwyczaj opisuje się wzorem Arheniusa lub wzorem Williama-Landel-Ferry'ego [9], bądź też innymi wzorami empirycznymi [6].

\section{Wyznaczanie charakterystyk dynamicznych konstrukcji z tłumikami drgań}

Równania ruchu konstrukcji z lepkosprężystymi tłumikami drgań można przedstawić w postaci [2]:

$$
\mathbf{M} \ddot{\mathbf{q}}(t)+\mathbf{C} \dot{\mathbf{q}}(t)+\mathbf{K q}(t)=\mathbf{p}(t)+\mathbf{f}(t)
$$

gdzie symbole $\mathbf{M}, \mathbf{C}$ i $\mathbf{K}$ oznaczają odpowiednio $n \times n$ wymiarowe macierze bezwładności, tłumienia i sztywności ramy, a $n$ wymiarowe wektory $\mathbf{q}(t), \mathbf{p}(t)$ i $\mathbf{f}(t)$ to odpowiednio wektor przemieszczeń, wektor sił wymuszających i wektor sił oddziaływania tłumików na ramę.

Wektor sił oddziaływania tłumików na ramę można przedstawić w postaci:

$$
\mathbf{f}(t)=\sum_{i=1}^{m} \mathbf{e}_{i} u_{i}(t)
$$

gdzie $\mathbf{e}_{i}$ wektor lokalizacji tłumika o numerze $i$ na ramie, a $u_{i}(t)$ oznacza teraz siłę oddziaływania i-tego tłumika.

Po wykonaniu na równaniach (1) - (3) i (11), (12) transformacji Laplace'a $\mathrm{z}$ zerowymi warunkami początkowymi otrzymuje się:

$$
\bar{u}=\sum_{r=0}^{m} \bar{u}_{r}, \quad \bar{u}_{0}=\left(k_{0}+s c_{0}\right)\left(\bar{q}_{k}-\bar{q}_{j}\right), \quad \bar{u}_{r}=\frac{s k_{r} \tau_{r}}{1+s \tau_{r}}\left(\bar{q}_{k}-\bar{q}_{j}\right)
$$




$$
\left(s^{2} \mathbf{M}+s \mathbf{C}+\mathbf{K}\right) \overline{\mathbf{q}}=\overline{\mathbf{p}}+\overline{\mathbf{f}}, \quad \overline{\mathbf{f}}=\sum_{i=1}^{m} \mathbf{e}_{i} \bar{u}_{i}
$$

W powyższych związkach $s$ jest zmienną Laplace'a, a symbol z nadkreśleniem oznacza transformatę Laplace'a odpowiadającej wielkości bez nadkreślenia (np. $\overline{\mathbf{q}}$ jest transformatą $\mathbf{q}(t)$ ).

Można wykazać (porównaj [2]), że

$$
\bar{u}_{i}=-\left[\left(k_{0 i}+s c_{0 i}\right)+\sum_{r=1}^{m} k_{r i} \frac{s \tau_{r i}}{1+s \tau_{r i}}\right] \mathbf{e}_{i}^{T} \overline{\mathbf{q}}
$$

co pozwala na zapisanie równania (14.1) w postaci:

$$
\left(s^{2} \mathbf{M}+s \mathbf{C}+s \mathbf{C}_{d}+\mathbf{K}+\mathbf{K}_{d}+\mathbf{G}_{d}(s)\right) \overline{\mathbf{q}}=\overline{\mathbf{p}}
$$

W równaniu (16)

$$
\mathbf{C}_{d}=\sum_{i=1}^{m} c_{0 i} \mathbf{e}_{i} \mathbf{e}_{i}^{T}, \mathbf{K}_{d}=\sum_{i=1}^{m} k_{0 i} \mathbf{e}_{i} \mathbf{e}_{i}^{T}, \mathbf{G}_{d}(s)=\sum_{i=1}^{m} \sum_{r=1}^{m} k_{r i} \frac{s \tau_{r i}}{1+s \tau_{r i}} \mathbf{e}_{i} \mathbf{e}_{i}^{T}
$$

Jeżeli w równaniu (16) podstawimy $\overline{\mathbf{p}}=\mathbf{0}$ to mamy do rozwiązania nieliniowy problem własny, w którym $s$ jest wartością własną, a wektor $\overline{\mathbf{q}}$ jest wektorem własnym. Omawiany problem własny rozwiązano metodą kontynuacji opisaną w [2].

Jeżeli układ jest podkrytycznie tłumiony to rozwiązaniem problemu własnego są liczby i wektory zespolone, parami sprzężone oraz wartości rzeczywiste i wektory rzeczywiste. Tymi ostatnimi nie będziemy się zajmować ze względu na ich mały wpływ na dynamikę konstrukcji z tłumikami drgań.

Zwraca się uwagę na możliwość takiego sformułowania rozpatrywanego problemu, które prowadzi do liniowego problemu własnego, ale o większym wymiarze niż problem tutaj otrzymany. Sformułowanie to jest opisane w [2].

Częstości drgań $\omega$ i bezwymiarowe współczynniki tłumienia modalnego $\gamma$ wyznacza się na podstawie zespolonych wartości własnych $s=\mu+i \eta$ ze wzorów:

$$
\omega^{2}=\mu^{2}+\eta^{2}, \quad \gamma=-\mu / \omega
$$

\section{Wyniki przykładowych obliczeń}

Obliczenia przeprowadzono dla ramy ścinanej z nieodkształcalnymi ryglami pokazanej na rys. 2. Całkowita masa każdej kondygnacji wynosi $m_{s}=60000 \mathrm{~kg} \mathrm{i} \mathrm{w} \mathrm{modelu} \mathrm{jest} \mathrm{ona} \mathrm{skupiona} \mathrm{na} \mathrm{poziomie} \mathrm{stropu.} \mathrm{Sztywności} \mathrm{na}$ zginanie słupów poszczególnych kondygnacji (tzw. sztywności pięter [2]) są zróżnicowane i wynoszą odpowiednio: 


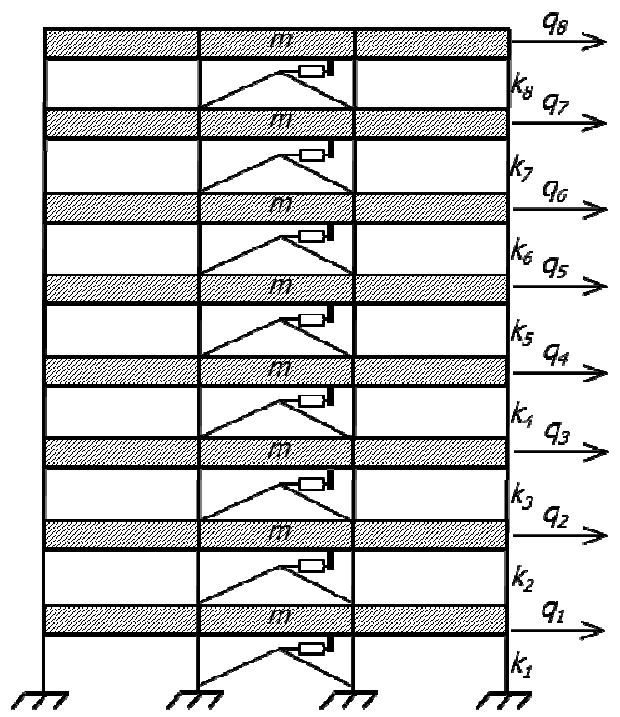

Rys. 2. Schemat ośmiokondygnacyjnej ramy z tłumikami drgań

Fig. 2. Scheme of the eight-storey shear frame with dampers

$k_{1}=k_{2}=441119 \mathrm{kN} / \mathrm{m}, k_{3}=k_{4}=275351 \mathrm{kN} / \mathrm{m}, k_{5}=k_{6}=152948 \mathrm{kN} / \mathrm{m}$, $k_{7}=k_{8}=93244 \mathrm{kN} / \mathrm{m}$.

Tłumiki lepkosprężyste zostały rozlokowane na wszystkich kondygnacjach. Dla każdego z nich przyjęto czteroparametryczny uogólniony model Maxwella, którego parametry określone dla temperatury odniesienia $T_{0}=0.2^{\circ} \mathrm{C}$ mają odpowiednio wartości: $k_{0}=10856 \mathrm{kN} / \mathrm{m}, k_{l}=1996809 \mathrm{kN} / \mathrm{m}, c_{l}=22963 \mathrm{kNs} / \mathrm{m}$, $c_{0}=0,0 \mathrm{kNs} / \mathrm{m}, \mathrm{m}=1$. Wartości funkcji przesunięcia $\alpha_{T}$ obliczano według wzoru Williama-Landela-Ferry'ego:

$$
\log \alpha_{T}=\frac{-C_{1} \Delta T}{C_{2}+\Delta T},
$$

gdzie $C_{I}=19.5$, a $C_{2}=80.2$.

Rysunek 3.a) przedstawia wpływ temperatury na pierwszą częstość drgań swobodnych układu. Na rysunku tym wyraźnie widać, że wartości pierwszej częstości drgań układu bardzo szybko maleją wraz ze wzrostem temperatury. Podobny efekt można zaobserwować w przypadku bezwymiarowego współczynnika tłumienia pierwszej postaci drgań (Rys. 3.b). Dodatkowo przeanalizowano relację, jaka zachodzi między temperaturą tłumików a funkcją przenoszenia układu dynamicznego. Reprezentatywne wyniki pokazano na rys. 4. Również w tym przypadku wpływ zmian temperatury jest bardzo wyraźny, szczególnie w zakresach stref rezonansowych. 

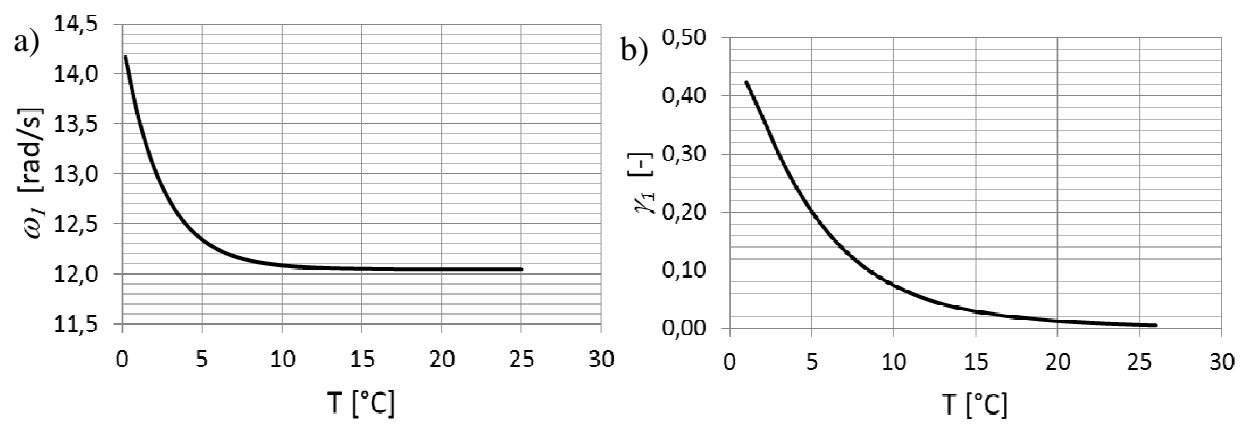

Rys. 3. Pierwsza częstość kołowa drgań swobodnych (a) oraz bezwymiarowy współczynnik tłumienia (b) pierwszej postaci drgań w zależności temperatury

Fig. 3. The first natural frequency (a) and the dimensionless damping ratio (b) of the first mode of vibration versus temperature

a)

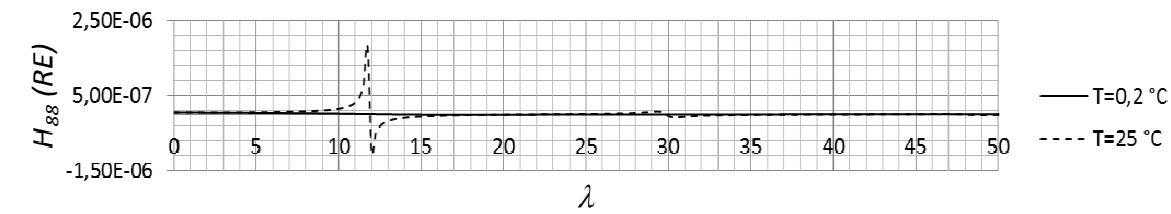

b)

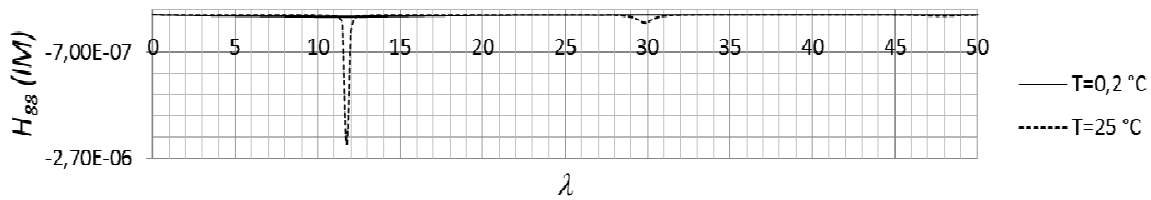

Rys. 4. Porównanie wartości elementu $H_{88}$ macierzy funkcji przenoszenia dla temperatury odniesienia $T_{0}$ i temperatury $T=25^{\circ} \mathrm{C}$ : a - część rzeczywista, b - część urojona

Fig. 4. A comparison of the element values of $H_{88}$ the matrix of frequency response function for reference temperature $T_{0}$ and $T=25^{\circ} \mathrm{C}:$ a) - the real part, : b) - the imaginary part

\section{Uwagi końcowe}

Celem przeprowadzanych badań była analiza wpływu zmian temperatury na charakterystyki dynamiczne konstrukcji z zainstalowanymi lepkosprężystymi tłumikami drgań. Wynika z niej, że zmiana temperatury ma wpływ tylko na parametry $c_{i}(i=0,1, . ., m)$ rozpatrywanego modelu tłumika lepkosprężystego. Przeprowadzone obliczenia pokazały znaczny spadek wartości częstości drgań swobodnych oraz bezwymiarowych współczynników tłumienia konstrukcji z tłumikami lepkosprężystymi wraz ze wzrostem temperatury lepkosprężystego materiału tłumików. Również wartości funkcji przenoszenia ulegają znacznym zmianom wraz ze zmianami temperatury. 


\section{Podziękowania}

Praca zostata wykonana $w$ ramach projektu finansowanego przez Narodowe Centrum Nauki, jako część projektu No. DEC/2013/09/B/ST8/01733, realizowanego w latach 2014-2016.

\section{Literatura}

[1] Soong T.T., Dargush G.F.: Passive Energy dissipation in structural engineering, Wiley, Chichester 1999.

[2] Lewandowski R.: Redukcja drgań konstrukcji budowlanych, Wydawnictwo Naukowe PWN, Warszawa 2014.

[3] Chang K.C., Soong T.T., Oh S.T., Lai M.L.: Effect of ambient temperature on viscoelastically damped structures, J. Struct. Engng, vol. 118, 1992, pp. 1955-1973.

[4] Kasai K., Sato D.: A constitutive rule for viscoelastic material considering heat conduction and heat transfer, The Second International Conference on Urban Earthquake Engineering, 2005, pp. 459-466.

[5] Tsai C.S.: Temperature effect of viscoelastic dampers during earthquakes, Journal of Structural Engineering, vol. 120, pp. 394-409.

[6] de Cazenove A.J., Rade D.A., de Lima A.M.G., Araujo C.A.: Numerical and experimental investigation on self-heating effects in viscoelastic dampers, Mechanical Systems and Signal Processing, vol. 27, 2012, pp.433-445.

[7] Makris N., Dargush G.F., Constantinou M.C.: Dynamic analysis of viscoelastic-fluid dampers, Journal of Engineering Mechanics, vol. 121, pp. 1114-1121.

[8] Lewandowski R., Przychodzki M., Pawlak Z.,: Influence of temperature on dynamic characteristics of structures with VE dampers, Proceedings of 3rd Polish Congress of Mechanics and 21st International Conference on Computer Methods in Mechanics, Gdansk, 2015.

[9] Nashif A.D., Jones D.I.G.: Vibration, damping, Wiley, New York 1985.

\section{INFLUENCE OF TEMPERATURE ON DYNAMIC PROPERTIES OF FRAMES WITH VISCOELASTIC DAMPERS}

\section{S u m m a r y}

In the paper an influence of temperature on dynamic properties of frames with built-in viscoelastic dampers is analyzed. Properties of dampers are described with a help of the generalized Maxwell model with parameters depending on temperature in dampers. The time-temperature superposition principle is used. Dynamic characteristics of considered systems are determined as the solution to the eigenvalue problem. Results of exemplary calculation are presented and briefly discussed.

Keywords: vibrations of structures, dampers, dynamic characteristics, influence of temperature

Przestano do redakcji: 07.06.2016 $r$.

Przyjęto do druku: 30.06 .2016 r.

DOI: $10.7862 / r b .2016 .51$ 